\title{
MONGOLISM IN AFRICANS
}

\author{
BY \\ JOSEPH LUDER and LATIMER K. MUSOKE \\ From Mulago Hospital, Kampala, Uganda
}

(RECEIVED FOR PUBLICATION MARCH 28, 1955)

It has been generally believed that mongolism is very rare among peoples of negro stock, and some authorities even go so far as to deny its existence among Africans, although conceding a greatly reduced incidence compared to that of white races among negro communities living as minorities in white countries.

The absence of any published reports of mongolism in Africans, and the clinical experience of psychiatrists working in Africa have strengthened this belief. The series of 173 cases of mental illness, analysed by Tooth (1950), in the Gold Coast contained no examples, and Carothers (1953) was unable to find a single case or even hear reports of any after a long experience of psychiatric conditions in East Africa. On these grounds he states categorically that the condition does not occur among negroes in Africa, and postulates that there must, therefore, be some noxious influence on foetuses of the white races in the early weeks of intra-

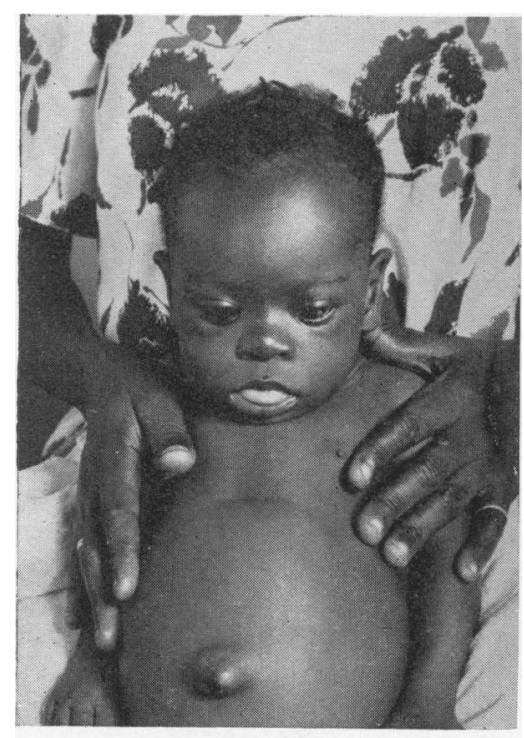

FIG. 1.

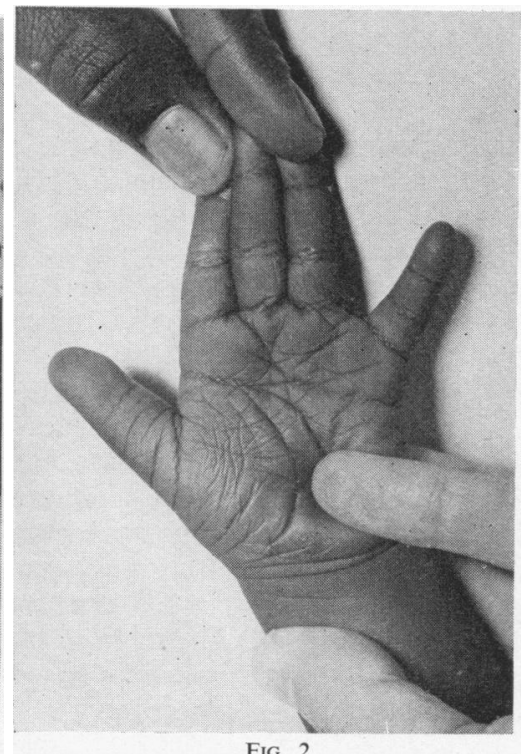

FIG. 2. uterine life which those of negro stock escape.

This paper reports five cases of mongolism seen in the vicinity of Kampala among the indigenous peoples in the space of one year, and suggests reasons why the conditions may have been frequently missed in the past. Four of the cases were seen at routine paediatric out-patient attendance at Mulago Hospital, Kampala, and one other at a welfare clinic near Kampala. No other form of selection was used.

\section{Case Reports}

Case 1. A female Ganda child was born in July, 1953. She was born after a normal full-term delivery, and was breast fed. In spite of adequate breast-milk she thrived poorly, and was afflicted with snuffles and occasional coughs. Cyanosis was noticed in the early months of life. By the age of 14 months she had only just begun to sit and made no attempt to stand. She was not able to say any recognizable words.

The parents had been married for nine years before the birth of this child. There were no previous children, but one miscarriage had occurred in the early years of the marriage.

The mother's age was given as between 30 and 35 , and the father's as about 35 .

On examination she was an undersized, underweight child, who could barely sit up unsupported. She was a cheerful child, who was constantly moving and groping with her hands. Cyanosis was marked in the palms and soles, and to a lesser extent in the nails. The facies were typically mongol (Fig. 1) with slanted eyes, depressed bridge of the nose, and prominent tongue, which was pointed when protruded. The skull was of normal shape, and at 14 months the anterior and posterior fontanelles were closed. There was no sagittal fontanelle 
and the sagittal suture was not obviously separated. The hands showed typical short little fingers and a transverse crease (Fig. 2), but the palmar ridges were poorly developed, and the position of the tri-radii could not be made out. The first and second toes were widely separated, with a moderately deep cleft between them.

There was considerable enlargement of the heart clinically and radiologically, with a loud systolic murmur to the left of the sternum, maximal in the third intercostal space. No thrills were present.

The child was markedly hypotonic, but there were no other abnormal signs in the nervous system. An umbilical hernia was present.

The mother's palmar tri-radii showed a normal angle.
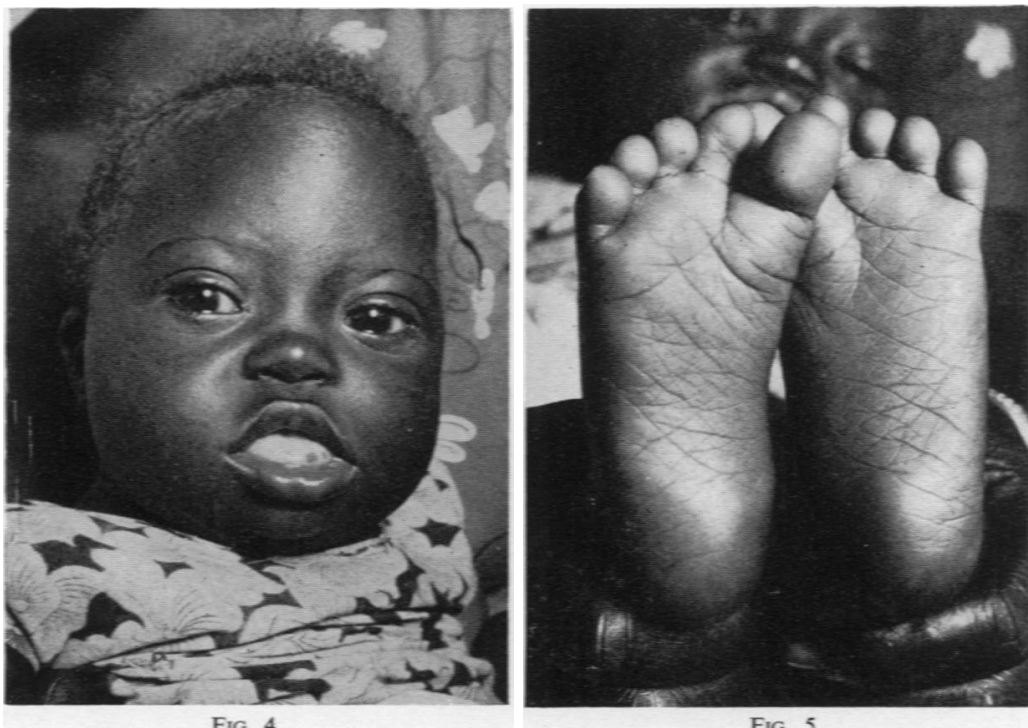

The mother's age was given as 39 , although she looked older. The father's age was not known.

Case 2. This was also a female Ganda child born in February, 1954.

She was a premature child of unknown birth weight. Breast feeding had been complemented with diluted cow's milk from birth. The child always appeared weak and thrived very poorly. She was brought up for advice at the age of 8 months because of general weakness and several recent attacks of diarrhoea.

There were three previous normal children. The gap between the patient and the next eldest child was 10 years.

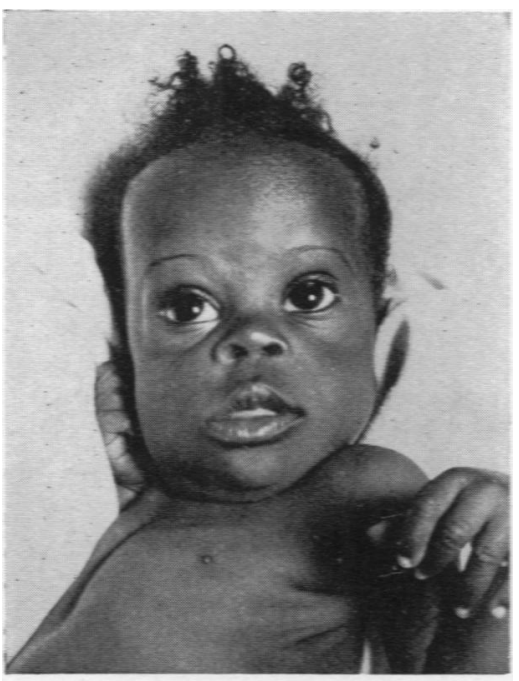

On examination she was grossly underweight (weight $8 \mathrm{lb} .1 \mathrm{oz}$.) lying limply in her cot and showing few movements. The nose was very small, with a depressed bridge, and the eyes were slanting. The epicanthic folds were marked (Fig. 3). The tongue was frequently protruded.

Palpation of the skull revealed separation of the sagittal suture, a sagittal fontanelle and a patent anterior fontanelle. The posterior fontanelle was closed.

The little fingers of both hands were short and incurving, but the tri-radii could not be clearly made out. The great and second toes were widely separated, with a wide plantar cleft between them. A small umbilical hernia was present.

Hypotonia was very marked in all limbs, and the child was unable to life up her head.

Attempts to interest her in toys produced little response.

Case 3. A female Lango child was born in December, 1953.

She was breast fed and thrived well. There were several attacks of upper respiratory infection in the early months and one of bronchopneumonia.

There were five siblings, of whom one had died. The ages of the parents were not known.

She was seen at the age of 9 months, and was a plump child, weighing approximately $17 \mathrm{lb}$.

She had a typical mongol facies, with slanting eyes, small button nose and small ears (Fig. 4). The tongue was large, smooth, protuberant, and had patches of pigmentation at the tip. She had marked snuffles.

In the skull, the anterior fontanelle was large, admitting three fingers, and the posterior fontanelle was closed, but about $1 \mathrm{~cm}$. in front of the latter was a small depression admitting the tip of a finger. 


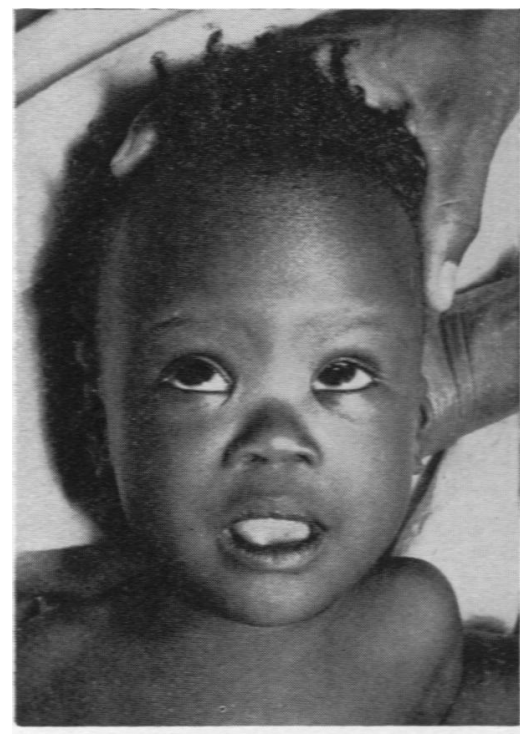

FIG. 6.

The little fingers were short, not reaching to the distal crease of the fourth fingers, and in the palms the transverse creases were coalesced into a single furrow. The proximal tri-radii of both palms were displaced distally forming the typical obtuse angle with the distal tri-radii.

The great and second toes were widely separated and a furrow was present in the sole between them (Fig. 5).

She was just able to sit up for a few seconds, but showed little interest in the surroundings and did not grasp objects offered to her.

The other systems were normal. folds, a prominent, frequentlyprotruded tongue which tended to be pointed, and low-set ears with irregular helices (Figs. 6 and 7). Marked snuffies were present.

In the skull, the anterior fontanelle was very large, admitting four finger-tips easily, and there was a patent sagittal admitting one finger-tip. The sagittal suture was slightly widened, and the posterior fontanelle was closed.

The little fingers were short and in-curved and showed only one transverse crease (Fig. 8), but the tri-radii of the palms could not be made out. In the feet, the big and second toes were widely separated, but there was no well-marked plantar furrow (Fig. 9). FIG. 7.
The child was not able to sit up unsupported, and hands in a coordinated fashion. He would hold a biscuit in his hand, but would not put it to his mouth, and soon tended to drop it. All limbs were markedly hypotonic.

Other systems were normal.

Case 5. A male Lango child was aged 1 year 2 months.

His early history was not known, and he was brought to hospital suffering from lobar pneumonia. Further questioning revealed that he was unable to stand even

Case 4. A male Ganda child was born in January, 1954.

He was breast fed but thrived well only for the first three months of life. He was first seen at 3 months of age, having had snuffies from the early weeks, and having developed a bulging of the sternum. In succeeding months he had frequent attacks of pyrexia and cough, and the weight gain was very poor.

There were four siblings, all well and mentally normal.

The mother's age was given as 28 to 29 , and the father's as 32 .

On examination, aged 9 months, he was a thin underweight child, weighing only 11 lb. $8 \mathrm{oz}$. The facial appearance was typically mongol, with slanting eyes, marked epicanthic

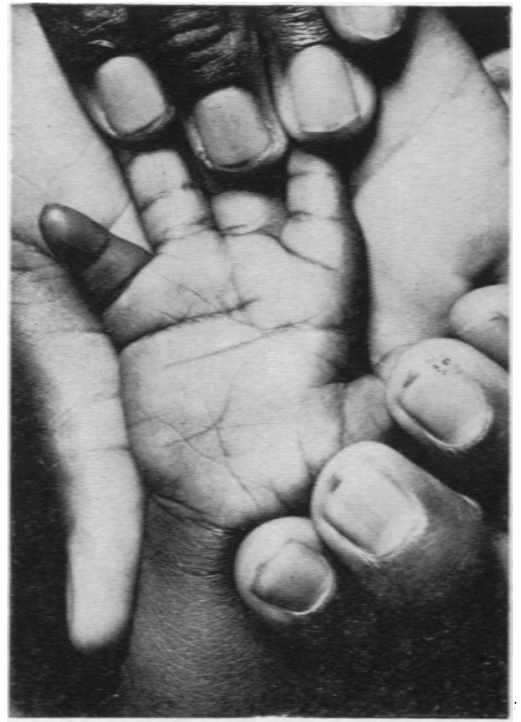

FIG. 8.

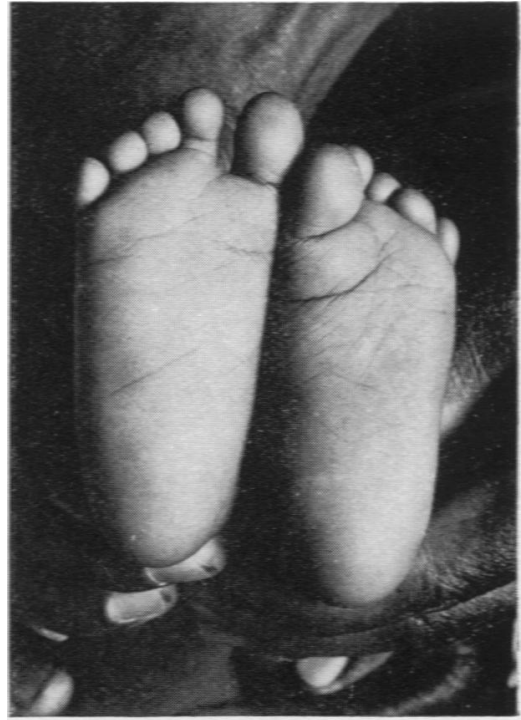

FIG. 9. 


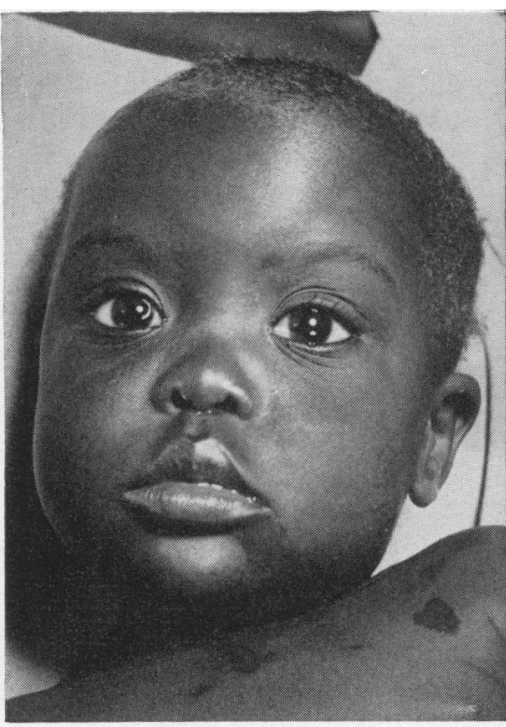

FIG. 10.

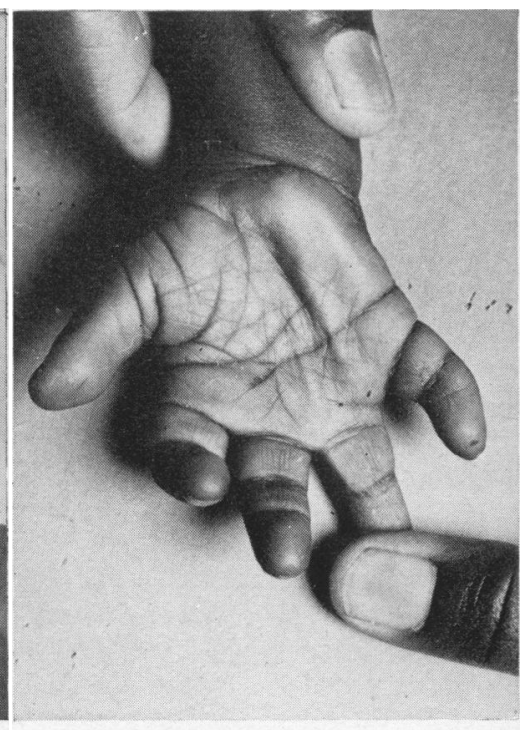

FIG. 11 ,

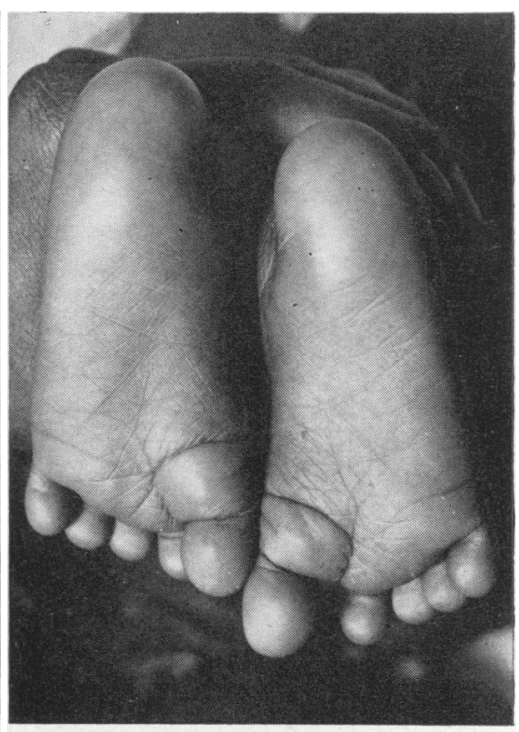

FIG. 12. with support, and said no recognizable words. He did however, hold objects in his hands and transfer them from one to the other.

There were two older siblings, aged 6 years and 4 years. Both were mentally normal.

The parents' ages were not known.

On examination, the facies were suggestive of mongolism, although not fully characteristic (Fig. 10). The eyes were widely spaced and slanting, although the epicanthic folds were not prominent. The tongue was of normal size and not protuberant.

In the skull the anterior and posterior fontanelles were closed, but there was a patent sagittal fontanelle.

The little fingers were very short and in-curving and possessed only one transverse crease, with a rudimentary second crease (Fig. 11).

There was very wide separation of the big and second toes with a deep plantar furrow (Fig. 12).

Other systems were normal.

\section{Discussion}

It is accepted that there is no single diagnostic criterion for mongolism, and that many of the characteristic features can be found from time to time in normal individuals (Penrose, 1954). Each of these characteristics, however, occurs with vastly greater frequency among mongols than among the general population, and a concentration of several of these factors in one individual would put the diagnosis beyond reasonable doubt. Among these characteristics Penrose (1954) lists epicanthic folds, fissured tongue, transverse palmar flexion creases, lax ligaments, short stature, high cephalic index, in-curving minimal digits and the dermal-ridge sign.

Some of these features are not recognizable at birth or in the early months of life, for instance, dermal-ridges or a fissured tongue (Carter and MacCarthy, 1951), and conversely a third fontanelle is a valuable though not pathognomonic sign in early infancy (Carter and MacCarthy, 1951; Hoyle and Franklin, 1954).

Table 1 sets out the frequency of nine typical features of mongolism in our cases, and it can be seen that four of the cases showed six or more features and one case showed four. This last case, although seeming perhaps to be disqualified, was

TABLE 1

THE DISTRIBUTION OF NINE TYPICAL MONGOL FEATURES IN THE CASES

\begin{tabular}{|c|c|c|c|c|c|c|c|c|c|c|}
\hline Case & $\underset{\text { (mths.) }}{\text { Age }}$ & $\begin{array}{c}\text { Slanting } \\
\text { Eyes }\end{array}$ & $\begin{array}{l}\text { Epicanthic } \\
\text { Folds }\end{array}$ & $\begin{array}{c}\text { Protuberant } \\
\text { Tongue }\end{array}$ & $\begin{array}{c}\text { Patent } \\
\text { Sagittal } \\
\text { Fontanelle }\end{array}$ & $\begin{array}{l}\text { Short } \\
\text { Fifth } \\
\text { Digit }\end{array}$ & $\begin{array}{c}\text { Separation } \\
\text { of Toes }\end{array}$ & Hypotonia & $\begin{array}{c}\text { Mental } \\
\text { Retardation }\end{array}$ & $\begin{array}{c}\text { Tri-radius } \\
\text { Sign }\end{array}$ \\
\hline $\begin{array}{l}1 \\
2 \\
3 \\
4 \\
5\end{array}$ & $\begin{array}{r}15 \\
9 \\
11 \\
11 \\
14\end{array}$ & $\begin{array}{l}+ \\
+ \\
+ \\
+ \\
-\end{array}$ & $\begin{array}{l}\overline{+} \\
\overline{+} \\
-\end{array}$ & $\begin{array}{l}+ \\
+ \\
+ \\
+ \\
-\end{array}$ & $\begin{array}{l}- \\
+ \\
+ \\
+ \\
+\end{array}$ & $\begin{array}{l}+ \\
+ \\
+ \\
+ \\
+\end{array}$ & $\begin{array}{l}+ \\
+ \\
+ \\
+ \\
+\end{array}$ & $\begin{array}{l}+ \\
+ \\
+ \\
+\end{array}$ & $\begin{array}{l}+ \\
? \\
+ \\
+ \\
+\end{array}$ & $\begin{array}{l}- \\
\overline{+} \\
-\end{array}$ \\
\hline
\end{tabular}


nevertheless recognized as a mongol at first sight by several colleagues, and there is no doubt that the facial appearance of mongols can be appreciated without always being capable of full analysis.

Apparent Rarity. How true is the widely-held belief that mongolism occurs much more rarely among negro peoples than among the white races? Published evidence on this point is contradictory. The views of Tooth (1950) and Carothers (1953) have already been mentioned and to these must be added the work of Thompson (1939) who found, in a large survey of mongolism in the U.S.A., that whereas negroes form $9 \%$ of the total population of the country, they supplied only $1 \%$ of all the mongols. These authors, however, were concerned mainly with case material of ages ranging from the middle years of childhood upwards. Tooth's 173 patients, for example, were all adults, and Carothers dealt with a mixed, mainly mental hospital population. Of perhaps greater significance, however, is the experience of Jelliffe (1954) who failed to find a single case during an extensive paediatric experience in Nigeria. This author concludes from this that where mongolism is to be found among the negro races, as in the U.S.A., it is due to the admixture of Caucasian strains.

There is little doubt that a more accurate estimate of the incidence of mongolism is obtained by surveys among newborn infants and infants. Where this has been done a different picture emerges. Thus Parker (1950), examining the records of 27,931 livebirths, found 29 mongols among 25,025 negro infants, an incidence of $1 \cdot 16$ per 1,000 , and 3 mongols among 2,905 white infants, an incidence of 1.03 per 1,000 . This difference is not statistically significant. These figures are rather lower than those given in other smaller series (Carter and MacCarthy, 1951; Benda, 1946), the difference being probably due to the difficulty of diagnosis at birth, and the large number of observers necessarily involved in such a large series. Benda (1946) states that possibly as many as $\mathbf{5 0} \%$ of mongol babies may be missed at birth. Important evidence is forthcoming from South Africa. Kahn (1955) says that about three cases are diagnosed each year among 3,000 African live-births, approximately the same incidence as at a neighbouring European maternity hospital.

It is clear, therefore, that the incidence must appear widely different in various regions of Africa. Much of the rarity is more apparent than real. The diagnosis will obviously be made much more rarely where obstetrical and paediatric services are few or absent. During the early months of life, the depress- ed nasal bridge and invariable snuffles of the mongol must frequently lead to a misdiagnosis of congenital syphilis. Mongols are nearly all stunted in height and thrive poorly during the first few years of life (Benda, 1946), and must often be considered as cases of malnutrition. This may, indeed, be superimposed as a result of the difficulty of feeding a mentally retarded child. Where a congenital heart accompanies the condition this may often obscure the underlying diagnosis.

Few mongols must see the light of day after the early years of life. They suffer a high mortality in childhood, estimated by Tredgold (1947) as $80 \%$ during the second half of childhood. A slightly lower figure is arrived at by comparing the incidence at birth of $1: 669$ live-births found by Carter and MacCarthy (1951) and that of $1: 2,000$ among school-children of between 10 and 14 years found by Penrose (1949). This mortality would be increased by the very high infant mortality in Africa.

Those who survive are generally amiable and quiet imbeciles, the majority able to walk and talk. Among primitive and illiterate communities they either probably escape detection as mental defectives, or are hidden away as objects of shame. In any case, where mental hospitals are few, the available beds will be reserved for dangerous or violent psychotics rather than the placid mongol. It is striking that among the 173 random examples of mental hospital inmates studied by Tooth (1950), mental defectives numbered only six.

Diagnosis. It is not the intention here to give full details of the diagnosis of mongolism; this has been covered fully by other authors (Tredgold, 1947; Benda, 1946). Certain difficulties, however, are met with in making the diagnosis in African children. The broad nose with depressed bridge of the negroid face will, to some extent, mimic the button nose of the mongol. Marked epicanthic folds do not occur as commonly as in European mongols, nor, in this small series, did it appear that a flattened occiput was so often seen. On the other hand, widely separated first and second toes, with a deep plantar cleft, was noted in all cases. Hypotonia is a less reliable sign in African cases because of the frequency of a much more widespread cause, namely, malnutrition. In the early weeks of life, when the diagnosis ought to be made, reliance must be placed on the skull signs, in particular a patent sagittal fontanelle and separated sagittal suture, a short in-curving little finger, often with a single transverse crease, slanting eyes and a protuberant pointed tongue. It must be emphasized that it is 
a combination of a number of signs which makes the diagnosis.

Incidence. It is also possible, however, that the true incidence is indeed somewhat lower among African races, and probably other communities also, where the average age of mothers is low. Maternal age is widely accepted as being the most important aetiological factor (Penrose, 1954; Carter and MacCarthy, 1951). The latter authors show that at the end of child-bearing life the incidence is twenty times that at the beginning. With this point in mind, we have examined the ages of all mothers delivered in Mulago Hospital, Kampala, in 1953.

Bearing in mind that the figures are somewhat vitiated because of the limited knowledge of ages among backward peoples, the following points emerge: (1) Out of 1,176 maternities only six occurred over the age of 40 , and only 41 over 35 $(3.6 \%)$. (2) Mothers under the age of 25 numbered $63.4 \%$ of all mothers delivered, while those over 30 numbered $14.6 \%$. Comparable figures for England are provided by the Registrar-General's Statistical Review for England and Wales (1947) quoted by Carter and MacCarthy (1951). There, mothers under 25 formed $29 \cdot 1 \%$ and mothers over 30 formed $40 \%$ of all maternities. Those over 35 formed

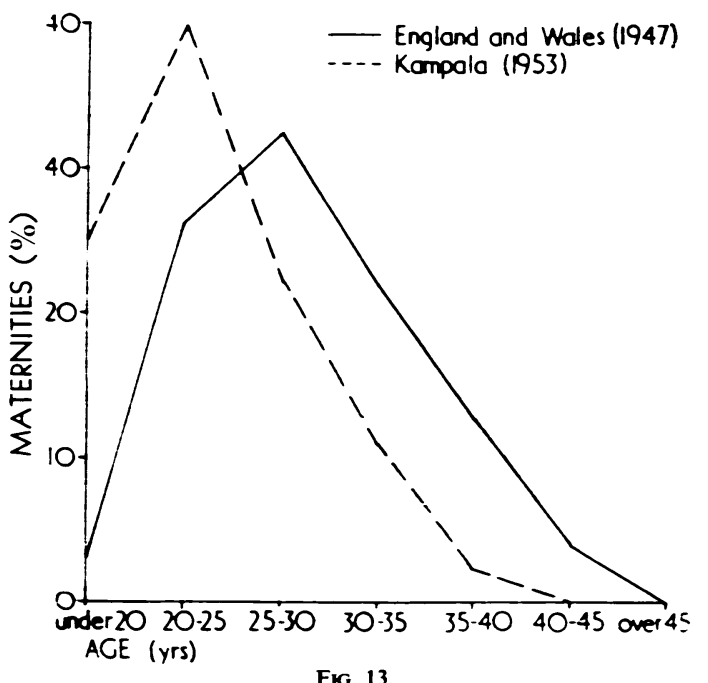

$17 \%$. There is, thus, a considerable concentration in the African mothers towards the younger end of fertile life. These results are set out in Fig. 13.

It would be interesting to see the results of a similar survey in Nigeria, in view of the probable rarity of mongolism there. At any rate it seems to be beyond question that the occurrence of the condition among the indigenous Ganda and Lango peoples of Uganda cannot be explained by the infusion of Caucasian blood.

An accurate estimate of the true frequency of the condition in this region must obviously await a large field survey. Meanwhile, it is permissible to conclude that the condition occurs in African races, possibly less often than among more advanced communities. With the increase in education, which is likely to raise the age of marriage for women and thus the age of motherhood, and with improvement in nutrition, which is likely to increase fertility, it seems that an increase in the incidence of mongolism must be anticipated.

\section{Summary}

Five cases of mongolism are reported from the Ganda and Lango tribes in the vicinity of Kampala. The condition is more common than has been believed from the great infrequency of the diagnosis in the past, but it is probable that the true incidence is still lower among Africans than among European peoples.

Thanks are due to Drs. H. C. Trowell and Hebe Welbourn for permission to quote details of cases under their care; to Professor C. Rendle-Short for access to obstetrical records for 1953; and to Dr. H. C. Trowell for his advice and help. We wish to thank the Hon. the Director of Medical Services, Uganda, for permission to publish.

\section{REFERENCES}

Benda, C. E. (1946). Mongolism and Cretinism. New York. Carothers, J. C. (1953). The African Mind in Health and Disease W.H.O. Monograph, No. 17. Geneva.

Carter, C. and MacCarthy, D. (1951). Brit. J. soc. Med., 5, 83.

Hoyle, C. M. and Franklin, A. W. (1954). Lancet, 1, 437.

Jelliffe, D. B. (1954). W. Indian med. J., 3, 164.

Kahn, E. (1955). Personal communication.

Parker, G. F. (1950). J. Pediat., 36, 493.

Penrose, L. S. (1949). J. ment. Sci., 95, 685.

(1954). Lancet, 2, 505.

Tredgold, A. F. (1947). A Text-book of Mental Deficiency, 7th ed.

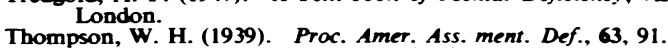

Tooth. G. (1950). Studies in Mental Illmess in the Gold Coast. [Colonial Res. Publ. No. 6.] London. 